\title{
Los pagos de parias como generadores de poder en los Condados Catalanes (1035-1076)
}

\section{Paria payments as power builders in the Catalan Counties (1035-1076)}

\author{
Adrián Elías Negro CoRtés \\ Universidad de Extremadura \\ anegro@unex.es
}

Fecha de recepción: 05-03-2018

Fecha de aceptación: 07-07-2018

\begin{abstract}
RESUMEN
El propósito de este artículo es analizar cómo las parias: tributos pagados por los musulmanes, en este caso de las taifas de Zaragoza, Lérida y Tortosa principalmente al conde de Barcelona, tienen un papel esencial a la hora de situar a este condado en un lugar preeminente en Cataluña durante el gobierno del conde Ramón Berenguer I (1035-1076). Después de una pequeña introducción veremos cómo mediante la inclusión de ciertas cláusulas en los juramentos de vasallaje el conde barcelonés se aseguraba el monopolio de los ingresos de parias y cómo formaba una red clientelar redistribuyendo el dinero que recibía. También utilizaba el dinero procedente de las parias para expandir su territorio: por un lado compraba condados de manera directa y por otro incentivaba el establecimiento de nobles en peligrosas zonas fronterizas.
\end{abstract}

PALABRAS CLAVE: Parias, Barcelona, Siglo XI, Ramón Berenguer I, taifas.

\section{ABSTRACT}

The aim of this article is to analyse how the parias, which are tributes paid by the Muslims, in this example from the taifas of Zaragoza, Lérida and Tortosa, mainly to the Count of Barcelona, played an essential role in establishing this county's prominence during the government of Count Ramón Berenguer I (1035-1076). After an introduction, we will see how by including certain terms and conditions in the vows of vassalage the Count ensured the monopoly of the income produced by the parias and how he redistributed the money among his vassals, thereby creating patronage networks. The Count also used the money from the parias to expand his territory: on the one hand he bought counties directly, and on the other and he used the money to help nobles establish themselves in dangerous frontier zones.

KEY WORDS: Parias, Barcelona, Siglo XI, Ramón Berenguer I, Taifas. 


\section{INTRODUCCIÓN}

El objetivo de este texto es demostrar cómo el condado de Barcelona utiliza las parias como elemento de control y vertebración del territorio. Lo primero que hemos de clarificar es qué entendemos por parias, nosotros las definimos como un pago anual que se realizaba en moneda por parte de un poder musulmán a otro cristiano bajo coacción militar en la península ibérica a cambio de un cese de las hostilidades o el mantenimiento de una situación de paz ${ }^{1}$. El fin último de estos pagos es obtener o mantener una tregua.

Para realizar este trabajo nos hemos basado principalmente en documentación de archivo procedente de Cataluña, en especial del Arxiu Comtal de Barcelona, que forma parte actualmente del Archivo de la Corona de Aragón, pero también hemos utilizado fuentes procedentes de otros lugares geográficos como Áger o Urgel. La tipología documental más utilizada para este trabajo han sido los juramentos de vasallaje, aunque también se han usado juramentos de fidelidad y alguna donación.

Comenzaremos por realizar una pequeña contextualización histórica. Durante el siglo $\mathrm{XI}$, los cristianos gozaban de la hegemonía militar tras el colapso del Califato de Córdoba y la posterior división de su territorio en débiles reinos de taifas, pero sus estructuras sociodemográficas eran demasiado débiles como para plantearse imponer su dominio de manera efectiva sobre grandes zonas de Al-Andalus. Así se llegó a la institucionalización de los pagos de parias como vía de aprovechar esa preeminencia militar, que de otra manera quedaría desaprovechada. El primer lugar donde encontramos rastros de estos pagos en la península ibérica es precisamente la zona que nos ocupa, esto es, los condados catalanes a partir de la década de 1040, quizás influidos por el tributo -usualmente denominado danegeld- que los últimos carolingios y primeros capetos pagaron a los vikingos entre 845 y $926^{2}$. Los conceptos de danegeld y parias son bastante cercanos, en ambos casos unos estados relativamente consolidados en situación de desventaja militar -la Francia postcarolingia y los reinos de taifas en la península ibérica- abonan tributos a poderes con un desarrollo estatal menor- vikingos y entidades políticas cristianas, respectivamente- al no poderles hacer frente en el campo de batalla. Además, esos tributos juegan un papel clave en el fortalecimiento de las estructuras estatales de los perceptores.

Las parias fueron un aspecto esencial de la interacción política entre cristianos y musulmanes durante la segunda mitad del siglo XI. Por supuesto, se realizan pagos de parias en otras cronologías, como los abonos realizados por el reino nazarí de Granada ${ }^{3}$. Los problemas principales en torno a las parias son dos, el primero establecer si implicaron una detención efectiva del avance cristiano hacia el sur y el segundo determinar qué impacto tuvieron en el desarrollo de las estructuras estatales cristianas. Los pagos implicaron una ralentización del avance conquistador, pero es evidente que los reinos cristianos carecían de la infraestructura política, económica y sobre todo, demográfica, de gestionar el territorio que podría haber caído en sus manos si hubieran avanzado hacia el sur ${ }^{4}$. Las dificultades

1 Para un mayor desarrollo de esta breve definición véase A. E. Negro Cortés, "Las parias abonadas por el reino de Granada (1246-1464). Aproximación a su estudio", Roda da Fortuna, 2, 1-1 (2013), p. 383.

2 E. Joranson, The Danegeld in France, Rock Island (Illinois), Augustana Printers, 1923.

3 Cf. A. E. Negro Cortés, "Las parias abonadas por el reino de Granada (1246-1464). Aproximación a su estudio", Roda da Fortuna, 2, 1-1 (2013), pp. 382-396.

4 Por cuestiones de espacio, no podemos detallar mucho estas explicaciones, por lo que debemos remitir al lector a otros trabajos nuestros en los que profundizamos más en la materia, a saber, A. E. Negro Cortés, "Las parias: una introducción general" en F. Sabaté y J. Brufal (ed.) Investigar l'edat mitjana, Lérida, Pagés Editors, 2018, pp. 43-53 y A. E. Negro Cortés, "Las parias en la historia medieval española" en M. Urraco y S. López (ed.) Catálogo de Investigación Joven de Extremadura, Cáceres, Universidad de Extremadura, 2017, pp. 255-258. 
a las que se enfrentó Alfonso VI tras la caída de Toledo en 1085 representan un buen ejemplo de esto.

El impacto de las parias en el fortalecimiento de las estructuras estatales cristianas es claro, pero su alcance exacto es aún objeto de discusión. Las parias recibidas por Aragón, Navarra $^{5}$ y la zona catalana son relativamente bien conocidas gracias a la evidencia documental, pero en Castilla el vocablo "parias" no aparece en la documentación hasta entrado el siglo XII, por lo que es mucho más complicado localizar los pagos. Paradójicamente, las parias cobradas por Castilla, aun siendo mucho más importantes en cuantía que las recibidas en la zona oriental de la península, son mucho peor conocidas.

La situación de los condados catalanes durante el siglo XI resulta complicada. Al principio del siglo, el conde de Barcelona ostenta una condición de primus inter pares. Barcelona es el condado más importante, pero no es la única entidad política de la zona catalana. Durante la primera mitad del siglo XI, el principal condado catalán es incapaz de plantearse una estrategia de avance contra territorio musulmán debido a que atravesaba una etapa de debilidad interna. Dada la incapacidad del poder barcelonés, pequeños magnates como Arnau Mir de Tost o Mir Geribert son claves en la lucha contra los musulmanes. Este desgobierno es solucionado por Ramón Berenguer I, conde de Barcelona entre 1035 y 1076, quien consigue la renuncia de sus hermanos Sancho y Guillermo a los territorios legados por su padre Berenguer Ramón y así consigue convertir al Condado de Barcelona en la principal entidad política de la zona, aunque el resto de los condados mantenían su independencia.

Conseguido esto, su siguiente objetivo es reducir el poder de los nobles, especialmente los que dominaban la frontera con las taifas de Lérida y Zaragoza. Estos nobles habían adquirido un gran poder debido a la necesidad que había en esa zona de líderes militares que pudieran encabezar la lucha contra el enemigo musulmán. El conde barcelonés consigue llegar a una serie de acuerdos con estos aristócratas en los que ellos reconocen la primacía de Ramón Berenguer I. Analizaremos en profundidad estos pactos posteriormente, dado que en muchos de ellos se habla de cobros y repartos de parias.

Pese a que el territorio correspondiente con la actual Cataluña estaba dividido en numerosas entidades políticas, los aristócratas más importantes gobernaban varios condados y además eran familia entre sí, lo cual facilitaba las cosas a la hora de negociar y de unificar varios señoríos en la misma persona. El papel de estas relaciones familiares en la conformación de la estructura política catalana durante el período fue puesto de manifiesto por Ruiz-Domènec desde su interesantísima visión antropológica ${ }^{6}$. Aunque luego surjan fricciones a la hora del reparto de las parias.

Por otro lado, examinaremos las entidades políticas que pagaron parias a los condados catalanes. Hasta 1009, Al-Andalus había estado unida en el Califato de Córdoba, pero a partir de esta fecha las disensiones internas en torno a quién debía ostentar el cargo de califa derivaron en una guerra civil -la fitna del Califato- que continuó oficialmente hasta 1031, fecha en la que finaliza oficialmente el Califato de Córdoba. Pero ya desde la década de 1010 Al-Andalus empieza a disgregarse en pequeñas entidades políticas llamadas reinos

5 Para un análisis más detallado del problema en este escenario, véase A. E. Negro Cortés, "Explotación económica de los musulmanes del valle del Ebro: parias y almotexenas abonadas a los reinos de Aragón y Navarra durante el siglo XI", Aragón en la Edad Media, 28 (2018), pp. 4-17 y C. Laliena, La formación del Estado feudal: Aragón y Navarra en la época de Pedro I, Huesca, Colección de estudios Altoaragoneses, 1996, p. 121 y ss.

6 J. E. Ruiz-Doménec, "Cataluña en 1025: Ios orígenes de una organización social”, Estudi General, 1-1 (1996), p. 95. 
de taifas. En la zona nororiental, la que nos ocupa, las taifas que tuvieron frontera con los condados catalanes y les pagaron parias son las de Zaragoza, Lérida y Tortosa. Valoraremos a continuación la complicada evolución política de estas tres entidades políticas islámicas, haciendo hincapié en las fechas en las que estuvieron unidas o separadas unas de otras.

De estas tres taifas, la más importante fue la de Zaragoza, gobernada desde 1038 por la familia hudí. Entre 1038 y 1046 la taifa de Zaragoza y la de Lérida estuvieron unidas, entre 1046 y 1078 llevaron una existencia independiente, luego entre 1078 y 1082 ambas taifas volvieron a estar unidas y por último desde 1082 hasta la conquista almorávide en 1102 volvieron a ser independientes.

En lo que respecta a la taifa de Tortosa, entre 1031 y 1061 fue independiente, entre 1061 y 1082 fue anexionada a la taifa de Zaragoza y desde 1082 hasta la conquista almorávide fue unida a la taifa de Lérida, formando ambas taifas un único bloque. Las parias que llegaron a Barcelona solían proceder de Lérida-Tortosa, pero también obtuvieron parias de la taifa de Zaragoza.

El tema de las parias ha sido tratado por algunos autores para la zona catalana. El primero que se refiere a estos temas es Balari, quien dedica un apartado concreto a hablar del tema. Para él, las parias son los tributos que pagaban los sarracenos a los príncipes cristianos en reconocimiento de su superioridad, entendiéndolo como un vasallaje. Basándose en documentación archivística hace una historia del cobro de parias por parte de Barcelona, Urgel y Cerdaña ${ }^{7}$. Se trata de un resumen muy completo para el momento (1899) basado en un trabajo archivístico concienzudo pero incompleto.

Otros autores que han escrito en fecha más reciente sobre el tema son Balañá, quien recogió un resumen de la situación a mediados del siglo $\mathrm{Xl}^{8}$, Sobrequés, Bonnassie y Kosto. También han presentado reflexiones sobre el tema a las que merece la pena aludir Zimmermann, Débax y sobre todo, Sabaté.

Bonnassie analiza un acuerdo de vasallaje de 1076-1078 entre los condes gemelos -Ramón Berenguer II y Berenguer Ramón II, hijos y sucesores de Ramón Berenguer Ique le sirve para desgranar las principales características del régimen de parias cobradas desde Zaragoza, Tortosa, Denia y Granada. No hay pruebas, más allá de este pacto, de que las taifas de Denia y Granada abonaran parias al condado barcelonés, por lo que dudamos fuertemente de que estos pagos tuvieran lugar, principalmente por su lejanía geográfica.

También hace referencia a la expedición de Ramón Berenguer II contra Murcia y cómo fue engañado por unos dinares de baja ley acuñados y entregados por Al-Mutamid, rey taifa de Sevilla. Además, reconoce el papel del Cid en el final del régimen de parias catalán, ya en la última década del siglo $\mathrm{XI}^{9}$. De todas formas, el interés principal de Bonnassie no era analizar la política y la expansión catalana, sino la economía.

Siguiendo la misma línea, Zimmermann apoya la visión de unas parias como prerrogativa que el conde de Barcelona necesita asegurarse y, por ello, le da una importancia capital en los acuerdos de vasallaje que firma ${ }^{10}$. También reconoce la importancia de las parias en la

7 J. Balari Jovany, Orígenes Históricos de Cataluña, San Cugat del Vallès, Instituto internacional de cultura románica, 1964, pp. 333-336.

8 P. Balañá i Abadía, Els musulmans à Catalunya (713-1153): assaig de síntesi orientativa, Sabadell, Ausa, 1993, p. 110.

9 P. Bonnassie, La Catalogne du milieu du $X^{e}$ a la fin du XI Siècle, Croissance et mutations d'une sociètè, Tome II, Tolouse, Université de Tolouse-Le Mirail, 1975, p. 867.

10 M. Zimmermann, "Et je t'empouvoirrai (potestativum te farei), à propos des relations entre fidélité et pouvoir en Catalogne au Xle siècle", Mediévales, 10, 1986, p. 19 
financiación de asentamientos fronterizos, con el ejemplo de Tarragona ${ }^{11}$. También Débax se muestra de acuerdo en que el conde de Barcelona busca proteger los pagos mediante una simple comparación con los juramentos de vasallaje en el Languedoc. En esta región no suele aparecer una cláusula en la que el vasallo jure no interferir con los ingresos del señor pero dicha cláusula aparece frecuentemente en los pactos catalanes ${ }^{12}$.

Salrach coincide plenamente con Bonnassie, afirmando que el asentamiento de la autoridad condal está relacionada con los pagos que, según él, se comienzan a recibir en 1046 y que en el decenio 1050-1060, para este autor, supondrían unos ingresos de cerca de 9.000 dinares al año ${ }^{13}$. Es muy complicado, con la documentación de la que disponemos, llegar a cifras exactas de ingresos anuales en concepto de parias, por lo que debemos tomar el montante anual propuesto con Salrach con mucho cuidado, teniendo en cuenta que se trata tan solo de aproximaciones.

Para Kosto, autor anglosajón, no hay ninguna duda de que los contactos económicos de Cataluña con Al-Andalus desde 950 son la causa del despegue económico catalán del siglo XI a pesar de los desórdenes feudales que asolaron la zona durante parte de la primera mitad de este siglo ${ }^{14}$. Él diferencia los pagos a contingentes militares cristianos y las parias, aunque está más interesado en analizar cómo se realizaban los acuerdos más que en el contenido de éstos.

Finalmente, Flocel Sabaté considera las parias como un elemento muy a tener en cuenta por las cortes condales a la hora de decidir hacia dónde orientar los avances, debiendo dirigir sus fuerzas hacia musulmanes que no abonaran tributos. Además, afirma que en la posición de preeminencia alcanzada por los condes catalanes como cúspide de la pirámide feudal juegan un papel clave las parias que estos reciben ${ }^{15}$.

Nuestro aporte a la cuestión consiste en el análisis de una serie de documentos archivísticos, mayoritariamente juramentos de vasallaje provenientes del Arxiu Comtal de Barcelona, que demuestran cómo Ramón Berenguer I otorga castillos fronterizos con AlAndalus, a priori posesiones poco apetecibles para los nobles catalanes, usando las parias para premiar a quienes se atrevían a hacerse cargo de estas fortalezas y para construir una red clientelar que le ayudó a pacificar la zona y a asentar la primacía de Barcelona sobre el resto de los condados catalanes.

\section{LOSJURAMENTOSDEVASALLAJE:PRIMEROSINDICIOSDECONCENTRACIÓN DEL PODER}

Cataluña es una región plenamente feudalizada en época de Ramón Berenguer I. En la cúspide de la pirámide feudal se sitúa el conde de Barcelona, en el momento que nos ocupa Ramón Berenguer I, y el resto de condes, ya sean más importantes como el de Urgel o Besalú o menos importantes se ligan a él mediante juramentos de vasallaje. Una cláusula que aparece repetidamente en estos acuerdos, que es la tipología documental básica que hemos usado para analizar cómo se usaron las parias como mecanismo de centralización del poder en Barcelona, es la prohibición explícita a los vasallos de interferir en los pagos de parias de los musulmanes.

11 M. Zimmermann, "Et je t'empouvoirrai...", pp. 32-33.

$12 \mathrm{H}$. Dèbax, "Les feudalitats al Llenguadoc i Catalunya. Algunes observacions sobre les divergències de l'evolució", L'Avenç, 202, 1996, p. 34.

13 J. M. Salrach, Història de Catalunya, Volum II: El procés de feudalització (segles III-XII), Barcelona, Edicions 62, 1987, p. 323.

14 A. J. Kosto, Making agreements in medieval Catalonia: power, order and the written world, 1000-1200, Cambridge, Cambridge University Press, 2001, p. 13

15 F. Sabaté, La feudalización de la sociedad catalana, Granada, Universidad de Granada, 2007, pp. 65-66. 
La primera referencia al cobro de parias que encontramos data de en torno a 1040, en un documento que probablemente hace referencias a esta institución. Es un juramento de fidelidad de Ermemir de Casteltallat, en el que este promete no arrebatar al conde barcelonés "illorum honorem quod habent in Hispania" ${ }^{16 "}$. Los únicos "honores" que el conde barcelonés podría obtener de Hispania, que en la documentación catalana del período se refiere al territorio andalusí, eran los pagos de parias, aunque la referencia no es explícita, como sí lo serán las que vamos a exponer a continuación.

Una fórmula más desarrollada y que sin duda corresponde a un pago de parias aparece en un documento de 1041-1044 en el que Ermesenda, vizcondesa de Gerona, jura fidelidad a Ramón Berenguer I. Incluido en el juramento de fidelidad hay una cláusula en la que se especifica que la vizcondesa no debía "engañar" a Ramón Berenguer I en lo relativo a las parias que se cobraban de Hispania "Et ego iam dicta Ermessindis no dezebrei prescripto seniori meo de sua vita [...] neque de ipsas parias de Hispanie quas ei convente sunt dare aut in antea erunt ${ }^{17}$ ". Además, parece deducirse de la cláusula anterior que estas parias ya venían siendo cobradas desde cierto tiempo atrás. Contamos con bastantes juramentos de fidelidad en los que se repite la cláusula antes referida, a veces con alguna variación en las palabras que utiliza pero con el mismo significado: el vasallo no podía traicionar al conde de Barcelona en asunto tan importante como el cobro de parias.

La repetición continua de esta fórmula en juramentos de vasallaje nos indica que para el conde de Barcelona el cobro de parias es un aspecto insoslayable a la hora de establecer su poder y una prerrogativa propia de la que carecían el resto de condes catalanes.

El procedimiento de captación de parias era el siguiente: los gobernantes musulmanes de las taifas trataban con el conde de Barcelona o con el de Urgel y luego estos redistribuían el dinero recibido al resto de vasallos según los pactos que tuvieran firmados. Para que este proceso no se viera perjudicado por nobles ambiciosos, Ramón Berenguer I incluía en los juramentos de vasallaje cláusulas como la que hemos visto en el caso de Ermesinda, que prohibían a los aristócratas entrometerse en el cobro de estas parias. El vizcondado de Gerona está lejos de la frontera con los musulmanes y es poco probable que una mujer encabezara una expedición contra territorio enemigo, pero aun así Ramón Berenguer I incluye esa cláusula en el juramento de vasallaje, lo cual nos hace pensar que se convirtió en una cláusula estándar de estos pactos.

Entre 1040 y 1049 nos aparecen en el archivo condal barcelonés hasta doce documentos que hacen referencia a entregas de parias. Once de ellos corresponden a juramentos de vasallaje como los dos que hemos expuesto, ya sea usando la fórmula críptica "ipsa honore que habent de Ispania ${ }^{18 "}$ o haciendo referencia explícita a parias ${ }^{19}$. Sin embargo, existe una tendencia a usar la primera fórmula en juramentos de vasallaje que ligaban al conde de Barcelona con señores menores y la segunda en vasallajes en los que el conde de Barcelona recibía el homenaje de señores más importantes, como Ermengol III de Urgel o el hermano de Ramón Berenguer I: Sancho Berenguer. Estos son los dos documentos en los que se hace referencia explícita a las parias, dejando claro que su percepción son prerrogativa exclusiva del conde barcelonés. Hay hasta 50 juramentos

16 G. Feliu i Montfort, y J. M. Salrach, Els pergamins de l'Arxiu Comtal de Barcelona de Ramon Borrell a Ramon Berenguer I, Lérida, Fundación Noguera-Pagés, 1999, Vol. II, Doc. 289.

17 G. Feliu i Montfort, y J. M. Salrach, Els pergamins de l'Arxiu Comtal de Barcelona..., Vol. II, Doc. 320.

18 G. Feliu i Montfort, y J. M. Salrach, Els pergamins de l'Arxiu Comtal de Barcelona...,Vol. II, Docs. 379, 371, 373,374 y 381.

19 G. Feliu i Montfort, y J. M. Salrach, Els pergamins de l'Arxiu Comtal de Barcelona..., Vol. II, Docs. 359 y 385. 
de vasallaje firmados durante este período similares a los que hemos expuesto aquí en los que se repiten continuamente las mismas fórmulas.

En muchos pactos de este estilo el conde barcelonés obligaba a su vasallo a colaborar militarmente con él con el objetivo de cobrar parias a los musulmanes, como por ejemplo el firmado en septiembre de 1054 con Guillem II, conde de Besalú ${ }^{0}$ o el firmado con Udalard II en mayo de $1058^{21}$. Como es natural, en juramentos de fidelidad-que para Feliù y Salrach son renovaciones de los juramentos de vasallaje a la muerte de alguno de los firmantesaparece también esta obligación, como en el de Ramón Folc, hijo de la vizcondesa Guilla de Cardona, de la década de $1050^{22}$.

\section{CONCESIONES SOBRE PARIAS COMO PRERROGATIVA CONDAL}

El conde de Barcelona, como poseedor de los derechos sobre las parias, también podía cederlos a otros nobles con el fin de incentivar la ocupación de peligrosos territorios fronterizos que a primera vista podían no resultar muy apetecibles. Poco poblados y susceptibles de ser atacados por aceifas musulmanas, en general ni nobles ni campesinos tenían ninguna motivación por habitar en estas zonas fronterizas, a pesar de que resultaban clave en la estrategia barcelonesa de expansión hacia el sur.

Un ejemplo de estas concesiones lo encontramos en la década de 1040, es una en la que los condes de Barcelona encomiendan a Berenguer, vizconde de Narbona, la ciudad y el condado de Tarragona. Como Tarragona en estos momentos es una ciudad deshabitada, en la frontera con los musulmanes y expuesta a ataques continuos, el conde barcelonés tiene que dar una serie de incentivos a Berenguer para que se instale allí, entre los que destacan 120 uncias de oro anuales procedentes de las parias ${ }^{23}$, salvo que sea el propio Berenguer el que cobre directamente a los musulmanes, en cuyo caso, el conde barcelonés no tendría que pagarle nada dado que ya está captando los pagos el propio Berenguer ${ }^{24}$.

Por tanto, es Ramón Berenguer I el que, ejerciendo su primacía, delega una parte de su propio poder, la recepción de parias, en el vizconde de Narbona, con el fin de animarle a repoblar Tarragona e incluso le ofrece la opción de recibir pagos de parias al propio vizconde de Narbona. Esto puede resultar incongruente con la política de centralización de

20 "Et iam dictus Guillelmus comes convenit iam dicto Remundo comiti ut adiutor sit ei a tenere et ad abere omnes ipsas parias quas hodie apprehendit de Ispania de qualibuscumque locis ille eas apprehendit, et alias parias quas adquisiturus erit predictus Remundus comes cum consilio iam dicti Guilelmi comitis", G. Feliu i Montfort, y J. M. Salrach, Els pergamins de l'Arxiu Comtal de Barcelona..., Vol. II, Doc. 437.

21 "Item convenit iam dictus Udalardus comiti et comitissae predictis ut auditor sit eis ad tenere et ad habere et ad guerregare et ad defendere ipsas parias de Hyspania, et ipsos chastros aut chastellos, alodios aut fevos, terras et honores, quas prescripti comes et comitissa hodie habent et adhuc adquisituri sunt deo Dante", G. Feliu i Montfort, y J. M. Salrach, Els pergamins de l'Arxiu Comtal de Barcelona..., Vol. II, Doc. 521.

22 "Et ego Reimundus iam dictus adiutor ero tibi a tenere et ad abere et defendere ipsum honorem et ipsas parias quas tu hodie habes de Ispania et in antea adquisiturus eris", G. Feliu i Montfort, y J. M. Salrach, Els pergamins de l'Arxiu Comtal de Barcelona..., Vol. II, Doc. 516.

23 "Et de ipsas naves [que vicecomes] Berengarius adduxerit ad iam dicta civitate Terragona, aud fecerit venire o ad ic fecerit ipsas parias uel ipsum [...]mente que ipsas naves comes fecerit, abeat iam dictus vicecomes ipsa medietatem. Et predictus comes uel comitissa donent ad [predicto] vicecomite de ipsam pariam que aprehendit de Ispania, per unumquenque annum, centum XXti uncias de auro.", G. Feliu i Montfort, y J. M. Salrach, Els pergamins de l'Arxiu Comtal de Barcelona..., Vol. II, Doc. 388.

24 "Et istas centum XXti uncias de auri suprascriptas, tantum donet eas Raimundus suprascriptus et Elisabet suprascripta ad Berengarius suprascriptus, usque que tales abeat unum aud duos sarrazenos de Ispania de ipsis qui pariam donent ad ipso comite, qui iurent a Berengarium suprascriptum quod donent ei istas centum XXti uncias de auri sine enganno de predicto Berengario", G. Feliu i Montfort, y J. M. Salrach, Els pergamins de l'Arxiu Comtal de Barcelona..., Vol. II, Doc. 388. 
los pagos que hemos explicado en el apartado anterior, pero ha de ser entendido como una concesión más que ofrecía el conde de Barcelona a su posible vasallo para convencerle de que se estableciera en una zona especialmente peligrosa.

De todas formas, la segunda parte del acuerdo matiza en cierta medida esta concesión: la cantidad de dinero que consiguiera el vizconde de Narbona de parias musulmanas en Tarragona se restaba del montante que debía pagarle Ramón Berenguer I, lo cual era ventajoso también para el conde barcelonés. Es muy probable también que esta cláusula existiera porque ambos ingresos procedían de la misma fuente, es decir, si los musulmanes de la zona fronteriza le entregaban el dinero al nuevo tenente de Tarragona ya no lo enviarían a Barcelona y viceversa.

Esta promesa de ingresos adicionales es también una manera de animar al vizconde de Narbona a mantener una actitud proactiva con respecto a la defensa del territorio, ya que si conseguía asegurarse unos ingresos superiores a 120 uncias de oro anuales como parias sus ingresos se verían incrementados.

Además, el documento nos revela el número de entidades políticas musulmanas que están pagando parias a Barcelona, "unum aud duos sarrazenos de Ispania de ipsis qui pariam donent ad ipso comite (Ramón Berenguer I)". Con la referencia genérica a Hispania no sabemos exactamente qué parias le están pagando a Ramón Berenguer I, pero pensamos que pueden ser Lérida, que se independizó de Zaragoza en 1046, y Zaragoza, puesto que hay referencias explícitas a las parias pagadas por ambas taifas en documentación posterior.

En otro documento fechado en noviembre de 1051, Ramón Berenguer I le encomienda a Arnau Mir de Tost $^{25}$, un importante noble fronterizo, señor de Áger, la tenencia del castillo de Camarasa, a $13 \mathrm{~km}$ de Balaguer -en aquel momento perteneciente a la taifa de Lérida-. Por tanto, es un castillo situado en zona de frontera. El conde barcelonés le concede el feudo al señor de Áger a condición de que Arnau le entregue a Ramón Berenguer I tres cuartas partes de los beneficios que produzca el castillo, pero podía conservar un cuarto para sí mismo.

Otra condición que se establece en el pacto es que si Balaguer paga parias, Ramón Berenguer tendrá que darle a Arnau Mir de Tost la mitad del dinero percibido ${ }^{26}$. Además se acuerda que si Ramón Berenguer muere, tendrá que entregar una parte de las parias de Zaragoza y Lérida a Arnau o sus herederos ${ }^{27}$. Por tanto, apreciamos cómo en fecha tan temprana como 1051 hay referencias explícitas a pagos de parias desde Zaragoza y Lérida a Barcelona.

\section{PACTOS CON GRANDES CONDADOS: URGEL Y CERDAÑA}

El conde barcelonés gobierna el condado más importante, pero ha de mantener también buenas relaciones con otros condes importantes de la zona catalana. Los siguientes condados más importantes eran los de Urgel y Cerdaña. Estos condes cuentan

25 F. Fité i Llevot, E. González i Montardit, Arnau Mir de Tost: Un señor de frontera al segle XI, Lérida, Universidad de Lérida, p. 165.

26 "Et, si iam dictus comes abuerit guerram cum Balager uel cum suis kastris et postea facit inde pacem, et acceperit pariam de Balager uel de suis kastris plusquam modo non accipit, donet ad iam dictum Arnallum medietatem de hoc quod inde acceperit", R. Chesé Lapeña, Col-lecció diplomàtica de Sant Pere d'Ager fins 1198, Volum I, Barcelona, Fundación Noguera, 2011, Doc. 30.

27 "Et, si iam dictus comes mortuus fuerit, similiter filius suus uel ipse, cui iam dictus comes relinquerit ipsos kastros, adtendat et faciat iam dicta conueniencia ad Arnal et filium suum, et donet ei supra nominato auere dum ipso acceperit pariam de Cesaraugusta aud de Lerida", R. Chesé Lapeña, Col/lecció diplomàtica de Sant Pere d'Ager..., Doc. 30. 
con potencial militar suficiente para lanzar expediciones contra territorio sarraceno y de captar parias, por lo que Ramón Berenguer I tenía que asegurarse mediante pactos de que no se le escapasen muchos ingresos por esta vía.

Por ejemplo, en noviembre de 1051 el conde Ramón Berenguer I acuerda con el conde Ermengol III de Urgel cederle en feudo el castillo de Cubells, en la frontera con la taifa de Lérida. Al igual que en el caso de Tarragona, Cubells está en una zona fronteriza, por lo que de nuevo Ramón Berenguer I ha de ofrecer incentivos para que el conde de Urgel se haga cargo del castillo. Sería un ejemplo también de cesión de parias como prerrogativa condal.

En este caso, Ramón Berenguer I le paga a Ermengol III 350 mancusos anuales o, si Ermengol era capaz de cobrar al menos 1.000 mancusos como parias de los musulmanes, Ramón Berenguer I dejaría de pagarle esos 350 mancusos ${ }^{28}$. Además, el conde de Urgel se comprometía a apoyar militarmente al conde de Barcelona si este decidía atacar a los musulmanes "de quibus non accipiat pariam", un tercio de las parias resultantes del ataque serían para Ermengol III y los dos tercios restantes para Ramón Berenguer I ${ }^{29}$. Deducimos de esta cláusula que el pago de parias era garantía de paz para los musulmanes, pues los ataques sólo podían ir dirigidos contra territorios sarracenos que no pagaran parias.

Al mes siguiente, en septiembre de 1058, Ramón Berenguer I y Ermengol III de Urgel realizan un pacto en el que se le concede al segundo el usufructo de los castillos de Puigroig y Pilça, ambos en el condado de Ribagorza. Una de las condiciones que Ramón Berenguer impone para conceder ese beneficio feudal es que Ermengol III no pacte tregua alguna con Alhagib de Zaragoza -que es Al-Muqtadir, al que se le está designando con el título de hadjib- si no es con permiso de Ramón Berenguer ${ }^{30}$ y viceversa, Ramón Berenguer I también debe recabar el acuerdo de Ermengol para pactar con Al-Muqtadir ${ }^{31}$. También se compromete Ermengol a colaborar con tropas en los ataques que Ramón Berenguer lance contra Zaragoza ${ }^{32}$.

La colaboración entre Ramón Berenguer y Ermengol tiene un propósito muy claro y no es otro que el de someter al pago de parias a la taifa de Zaragoza, más poderosa que LéridaTortosa, como se pone de manifiesto en este documento. Por separado no tienen la fuerza suficiente, pero juntas Barcelona y Urgel pueden plantearse conseguir parias de Zaragoza.

El reparto de las parias zaragozanas es el siguiente: dos tercios van para Barcelona y el tercio restante lo recibirá Urgel ${ }^{33}$. Como también se puede observar en la documentación

28 "Et si potuerit ipse Raimundus facere ut Ermengaudus comes acciperet per singulos annos mille mancosos ex partibus Hispaniae de tale auro quale hodie accipit Raimundus comes de Hispania de illis sarracenis, de quibus nichil solitus sit accipere, dum ille eous habuerit, non requirat supradictos trecentos quinquaginta mancosos ad Reimundum comitem et habeat istos mille pro supradictis trecentis quinquaginta", G. Feliu i Montfort, y J. M. Salrach, Els pergamins de l'Arxiu Comtal..., Vol. II, Doc. 399.

29 "Convenit iterum Ermengaudus ut si Reimundus comes voluerit secum ducere eum super tales sarracenos de quibus non accipiat pariam, ipse Ermengaudus sequatur eum et adiuvet ad eum sine suo enganno. Et si Deus ibi dederit ad Reimundum pariam aut dona quae sarraceni ei donent, terciam partem habeat inde Ermengaudus comes", G. Feliu i Montfort, y J. M. Salrach, Els pergamins de l'Arxiu Comtal..., Vol. II, Doc. 399. 30 "non habeat cum Alhabid nec pacem nec trevam nec ullam societatem qui pacem similet nec treuvam nec ille nec homo per eum, nec per ullum nuncium non dirigat ei sine consilio et absolvimiento de supradicto comite Raimundo et de supradicta Almodi comitissa", F. M. Rosell, Liber Feudorum Maior: cartulario real que se conserva en el Archivo de la Corona de Aragón, Barcelona, CSIC, 1945, Doc. 148.

31 "Conveniunt etiam Raimundo comite supradicto, et Almodis, comitissa predicta, ad supradicto comite Ermengaudo ut de ista hora in antea non habeant cum Alhagib nec pacem, nec treuvam, nec ullam societatem qui pacem nec treuvam similet, nec illos nec homo per eos nec ullum nuncium non dirigant ei sine consilio et absolvimento de supradicto comite Ermengaudo", F. M. Rosell, Liber Feudorum Maior, Doc. 148.

32 F. M. Rosell, Liber Feudorum Maior, Doc. 148.

33 "Et quando fecerint pacem supradictos comites et iam dicta comitissa Almodis cum Alhagib, sine eorum 
aragonesa, hay una voluntad de que la paria que paga la taifa hudí vaya creciendo con el tiempo, se espera que Zaragoza vaya pagando cada vez más dinero, por ello se recoge una cláusula que contempla qué sucederá con esos ingresos extras ${ }^{34}$.

Ramón Berenguer I reconoce la posibilidad del conde de Urgel para negociar y captar parias de enemigos musulmanes, la cual niega en condiciones normales al resto de condes con los que realiza pactos, pero se asegura de mantener un estatus superior recibiendo más dinero, dos tercios frente al tercio que se llevaría el conde pirenaico si se recibieran parias de Zaragoza.

Otro acuerdo entre estos dos mismos condes, fechado en julio de 1063, representa un cambio en esta concepción. Es un pacto en el que se le renueva al conde Ermengol III el usufructo del castillo de Puigroig y se le confirma la concesión del castillo de Cubells. Una parte del documento está dedicada a confirmar el pacto de 1058, el reparto que se establece es el mismo que en 1058, un tercio para Urgel y dos tercios para Barcelona.

Se reitera que Ermengol no puede negociar treguas con Zaragoza sin el consentimiento de Ramón Berenguer pero, al contrario que en el documento de 1058, no hay una cláusula que requiera a Ramón Berenguer consultar con Ermengol a la hora de pactar treguas con los musulmanes. En 1062 el conde de Urgel, que sigue siendo Ermengol III, promete de nuevo fidelidad al conde de Barcelona y se compromete a darle un tercio de las tierras y los bienes que obtenga en un ataque a los sarracenos, excepto del castillo de Tragó de Noguera.

Un aspecto muy interesante de este documento es que aparece una deuda de Lérida y Zaragoza con Ermengol III ${ }^{35}$. Se cita a ambos reyes taifa, Alfagib, utilizando el título de hadjib para referirse a Al-Muqtadir y a Al-Muzaffar de Lérida, al que se cita por su nombre. Ramón Berenguer se compromete a hacer que Lérida y Zaragoza paguen los atrasos que deben a Urgel.

De noviembre de 1058 data otro acuerdo de infeudación de una zona fronteriza con la taifa de Lérida, la marca de Oluges, que es concedida en feudo por Ramón Berenguer I a Ramón I Guifré, conde de Cerdaña. Dado que se trata de un territorio peligroso, Ramón Berenguer I le concede al conde de Cerdaña 309 uncias anuales al peso de Barcelona: 10 mancusos por uncia. A cambio, el conde de Cerdaña tenía que apoyar al conde de Barcelona en sus acciones militares contra los reinos taifas de Zaragoza y Lérida con el objetivo de recuperar las parias que les venían abonando - de lo que cabe deducir que en fecha anterior a noviembre de 1058 los reyes taifas de Zaragoza y Lérida habían dejado de pagar parias ${ }^{36}$. A pesar de ello, sabemos que en ese momento se están cobrando parias de Tortosa, que consigue mantener su independencia gracias a estos pagos ${ }^{37}$.

parias, habeant duas partes comite Raimundo et comitissa Almodis et terciam partem Ermengaudo comite", F. M. Rosell, Liber Feudorum Maior, Doc. 148.

34 "Et si adcrescerint eis parias de Alhagib, quomodo adcrescerint ad comitem Raimundo et ad comitissa Adalmodis, secundum quod de eo solent accipere parias, ita faciant quod eo modo adcrescat paria de Alhagib", F. M. Rosell, Liber Feudorum Maior, Doc. 148.

35 F. M. Rosell, Liber Feudorum Maior., Doc. 149

36 "Et item convenit Remundus, Barchinonensis comes, ad Remundum, Cerritanensem comitem, ut si perdiderit ipsam pariam quod Remundus, Barchinonensis comes, ei fecerit acaptar de Saragoça aut de Lerida, per ipsas hostes aut chavalgadas aut per ipsa guerra quod predicto Barchinonensi comite fecerit, aut faciat illi ipsa paria acaptar de alio sarraceno aut predictus Barchinonensis comes emendet ipsa paria ad iam dicto Cerritanensi comite dum ipsa guerra duraverit, et postea non faciat finem cum ipso sarraceno donec recuperatam habeat ipsam pariam quomodo eam habebat antea quam ipsam guerram fuisset. Et si non potest illi acaptar ipsa paria de domnos de Saragoça et de Lerida, non se'n mittat in nullum suum dampnum", G. Feliu i Montfort, y J. M. Salrach, Els pergamins de l'Arxiu Comtal...,Vol. II, Doc. 530.

37 "Et similter adiutor sit illi de ipsas terras de Tortuosa, unde predictus Barchinonensis comes pariam 


\section{LA MANIFESTACIÓN EXTERIOR DEL DINERO OBTENIDO}

A partir de mediados de la década de 1040 comienza a haber indicios en el condado de Barcelona de que se maneja una cantidad de dinero apreciable. Por ejemplo, en 1046 se inicia la construcción de la Catedral de Barcelona. La entrada de los Anales de Cataluña correspondiente al año 1046 la describe de la siguiente manera:

Empeçaron los ilustres Condes Berenguer y Doña Isabel triunfantes de los moros, agradecidos al Cielo por las conseguidas victorias, la suntuosa fábrica de la Cathedral de Barcelona, que estava muy derruida por la antigüedad y contratiempos: tomaron tan a pecho la obra, que en breve tiempo la vieron levantada, como veremos, ofrecieron varias rentas assí a la Iglesia como al Cabildo, verdaderamente católicos ${ }^{38 "}$.

El dinero que se utilizó para volver a erigir la catedral barcelonesa provenía probablemente de las parias. El inicio del pasaje, que alude a las victorias conseguidas contra los moros y el final, donde se conceden rentas, dejan escaso lugar a la duda. Además, se aprecia un aumento significativo en el número de actas de consagración de iglesias entre 1040 y 1069 en comparación con los períodos inmediatamente anteriores y posteriores, coincidiendo con el período de mayor cobro de parias, lo cual significa que hay un repunte en la construcción de edificios religiosos aprovechando estos ingresos adicionales ${ }^{39}$.

En noviembre de 1056, la donación esponsalicia de Ramón Berenguer a su mujer la condesa Almodís de la Marche con motivo de la boda de ambos incluye referencias a parias. Entre los muchos bienes que se le conceden a Almodís -entre los que destaca el condado de Gerona- aparecen cantidades de dinero procedentes de las parias de Zaragoza y de Lérida $^{40}$. Se le dan a Almodís 100 mancusos de lo recaudado en Zaragoza pero de Lérida se le da todo, de lo que podemos concluir que las parias pagadas por la taifa zaragozana eran superiores a las que se cobraban de Lérida y que en esa fecha se estaban captando tributos de ambos territorios.

También encontramos en la donación esponsalicia el propósito de cobrar más parias ${ }^{41}$, es decir, se pretendía que el dinero que los musulmanes pagaban fuera incrementándose año a año, cláusula que ya hemos tenido oportunidad de analizar en pactos como el firmado con el conde de Urgel. Si las parias de Zaragoza se incrementaban, Almodís seguiría cobrando solo 100 mancusos, era lo mismo, pero si Lérida pagaba más la situación económica de la condesa mejoraría, ya que todos los ingresos que se obtenían de Lérida se entregaban a Almodís. Estos planes de qué hacer en caso de cobrar más nos hacen pensar que

prehendit.", G. Feliu i Montfort, y J. M. Salrach, Els pergamins de l'Arxiu Comtal..., Vol. II, Doc. 530; F. Sabaté, Història de Lleida. Volum 2: Alta Edad Mitjana, Pagès, Lérida, 2003, p. 137.

38 N. Feliú de la Peña, J. Puyol y J. Sobrequés i Callicó, Anales de Cataluña, Barcelona, Base, 1999, p. 302, año 1046

39 J. Puig i Cadafalch, A. de Falguera y J. Goday i Casals, L'Arquitectura romanica a Catalunya, Vol II, Institut d'Estudis Catalans, Barberà del Vallés, 2001 (ed. facsímil), pp. 330-331; P. Bonnassie, Cataluña mil años atrás (siglos X-XI), Barcelona, Península, 1988, p. 316.

40 "Dono, insuper, tibi ipsam paria que datur mihi de Lerita cum ipsa eciam que conventa est mihi dare inde et cum ipsa, eciam, quam, Deo dante, adcrescere et addere potuero et potueris. Et dono tibi centum mancusos per unumquenque mensem de ipsa paria que datur mihi de Saragoza", F. M. Rosell, Liber Feudorum Maior, Doc. 489.

41 "ut, postquam, Deo dante, potuerimus adscrescere prenominatam pariam de Lerita tantum ut centum mancusi addantur et donentur tibi de predicta paria de Lerita, tales quales mihi exeunt de Saragoza, tu, predicta Almodis, relinque istos centum de Saragoza et accipe illos additos centum de Lerita", F. M. Rosell, Liber Feudorum Maior, Doc. 489. 
efectivamente la cuantía de las parias iba aumentando a medida que pasaban los años, ya que es una cláusula bastante repetida en la documentación de la que disponemos.

Ramón Berenguer I también compra algunos condados ${ }^{42}$ en el sur de Francia como Carcasonne o Rhazés. Estos son los principales, pero hay varios ejemplos ${ }^{43}$ más de compra de condados en el Mediodía francés. También adquirió de su abuela la condesa Ermesenda, que se había resignado mal a perder el poder del que disfrutó mientras fue regente de su hijo ${ }^{44}$, los derechos que alegaba ella tener sobre los condados de Barcelona, Gerona, Manresa y Vic.

\section{PROBLEMAS ASOCIADOS A LA CENTRALIZACIÓN DEL COBRO DE PARIAS}

Los más afectados por la política de centralización del cobro de parias fueron los nobles que poseían pequeños territorios en la frontera con los musulmanes, a los que se les privaba de una importante fuente de ingresos. Un ejemplo claro es el caso de Mir Geribert.

En julio de 1058 se emite la sentencia contra Mir Geribert. Este personaje, nieto del conde Borrell II y cuyas propiedades estaban en la zona del Penedès, se rebeló junto con otros nobles de la zona contra Ramón Berenguer I por una serie de razones entre las cuales destacaba la imposibilidad de captar parias de los territorios musulmanes. Ruiz-Domènec no duda en calificarle como amenaza directa a la conformación de la sociedad feudal catalana del período ${ }^{45}$. En 1058 la rebelión está ya completamente sofocada, pero lo interesante de la sentencia es que se obliga a Mir Geribert a reintegrar las parias que Ramón Berenguer I había dejado de percibir debido a su rebelión y a comprometerse a no volver a interferir en los pagos de parias ${ }^{46}$, tanto él como su esposa y sus herederos ${ }^{47}$. Aparte de lo dicho en la sentencia, otro hecho que muestra las buenas relaciones que debían existir entre el conde rebelde y los sarracenos fue que se exilió en Tortosa tras el final de su confrontación con el poder condal.

La rebelión de Mir Geribert es un ejemplo de cómo el conde de Barcelona había impuesto su control férreo sobre los abonos monetarios. Los nobles, sobre todo de zonas fronterizas, estaban descontentos porque no podían atacar a los musulmanes, ya que las parias que los sarracenos abonaban al conde de Barcelona eran precisamente a cambio de no ser invadidos. Por tanto, es natural que el conde barcelonés no permitiera expediciones contra territorio musulmán.

Así, los nobles fronterizos, que eran normalmente los que sufrían las consecuencias de las aceifas musulmanas, no participaban de las ganancias del sistema, puesto que las parias eran abonadas directamente a Barcelona y luego era el conde quien redistribuía las ganancias entre sus afectos, añadiendo nobles a su red clientelar. El ejemplo de Mir Geribert

42 S. Sobrequés, Els grans comtes de Barcelona, Barcelona, Vincens Vives, 1961, p. 82; J. Zurita, Anales de Aragón, (ed. A. Canellas), Zaragoza, Institución Fernando el Católico, CSIC, 1976, p. 75.

43 F. M. Rosell, Liber Feudorum Maior, Docs. 156, 214, 490, 815, 819, 825 y 826.

44 J. M. Mínguez Fernández, La España de los siglos VI al XIII: guerra, expansión y transformaciones, Pamplona, Nerea, 2004, pp. 219-220

45 J. E. Ruiz-Domènec, L'Estructura feudal: sistema de parenitu i teoria de l'aliança en la societat catalana (c. 980-c. 1220), Sant Boi de Llobregat, Edicions del Mall, 1985, p. 66.

46 "Predictus Miro redintegrare et recuperare debet, sicut erat illa die quando venit predictum castrum in potestate Mironis, quando comes eum illi dedit [...] Et iudicaverunt predicti iudices de ipsam pariam de Ispania unde predictus comes se querelavit de iam dictum Mironem: quod predictus Miro debet iurare manibus quod predictus comes non perdidit predictam pariam neque onorem de Ispania per consilium neque per ingenium neque per stabilimentum de predicto Mirone", G. Feliu i Montfort, y J. M. Salrach, Els pergamins de l'Arxiu Comtal..., Vol. II, Doc. 523.

47 G. Feliu i Montfort, y J. M. Salrach, Els pergamins de l'Arxiu Comtal...,Vol. II, Doc. 525. 
demuestra los desajustes de este sistema, que permitieron a Barcelona incrementar su poder sobre el resto de condados catalanes pero que creaba descontento entre los nobles que quedaban fuera de la red clientelar.

\section{EL CONDADO DE URGEL: REDISTRIBUIDOR MENOR EN LA RED DE PARIAS CATALANAS}

El condado de Urgel trató de incrementar su poder en su zona de influencia principalmente, el Prepirineo leridano- usando las mismas prácticas que su homólogo barcelonés pero a menor escala. Contamos con testimonios que nos confirman que Urgel captó parias "ex partibus Hispaniae" en una donación correspondiente a 1048 realizada por Ermengol III de Urgel y su madre Constancia cuando Ermengol contaba con quince años de edad ${ }^{48}$. Las taifas de las que se está captando dinero son la de Zaragoza y la de Lérida, como demuestra un juramento de fidelidad de Ermengol III al obispo Guillem de la Seu datado entre 1042 y $1065^{49}$. Se trata de una donación del conde urgelense, quien cobraría las parias y luego donaría una cantidad de dinero procedente de las mismas al obispo de Urgel.

En agosto de 1058, Ermengol III de Urgel le concede a Arnau Mir de Tost la tenencia del castillo de Caserras, muy cerca del castillo de Purroy. En el siglo XI esta zona era designada como el sur del condado de Ribagorza, a la que también pertenecen los castillos de Purroy y Pilzán, situados muy cerca del castillo de Caserras. De las parias que se pudieran obtener -no se especifica de dónde, se dice "de partibus Hispaniae"- un cuarto iría para el conde de Urgel y los tres cuartos restantes para Arnau ${ }^{50}$.

Además, el conde de Urgel le tiene que pagar a Arnau 200 mancusos en junio, procedentes de las parias de Zaragoza y 100 en julio, que saldrían de las parias pagadas por la taifa de Lérida ${ }^{51}$. Si las parias que pagaban alguna de las dos taifas se incrementaban, también se incrementaría la cantidad que recibía Arnau por la tenencia del castillo. Así, el conde de Urgel se erigía también en redistribuidor de parias.

De octubre de 1059 data otro pacto entre Arnau Mir de Tost y Ermengol de Urgel en el que encontramos una cláusula en la que se indica que Arnau Mir de Tost tendrá que ayudar a Ermengol de Urgel a cobrar las parias procedentes "ex partibus Hispaniae"52. Ya hemos

48 J. Villanueva, Viage literario á las iglesias de España, Tomo 10, Madrid, Real Academia de la Historia, 1821, p. 184.

49 "Et ipsa paria de Ispania de Cesaraugusta uel de Lerida que tibi [el obispo] est conventa vel scribta non tibi erit vetata vel tolta per meum consilium neque per meum ingenium" C. Baraut, "Els documents, dels anys 1051-1075, de l'Arxiu Capitular de la Seu d'Urgell" en Urgellia, 6 (1983), p. 239, doc. 891.

50 "est uoluntas Dei quod ueniant parias aut [...] de ista era in antea ex partibus Hispanie ad iam dicto castro, habeat inde iam dictus comes ad suum dominicum ipsam quartam partem, et Arnallus predictus ipsas tres partes", R. Chesé Lapeña, Col·lecció diplomàtica de Sant Pere d'Ager, Doc. 39

51 "et predicto comite donet ad iam dicto Arnallo per guarda et per castellania de predicto [castro] de paria quomodo inconuentum ei est addare de Zaragoza de uno mense omni tempore, et hoc est mancusos CC de auro mundo; et alio mense de parias que accepit de Lerida et inconuentum est ei ad dare omnique tempore, et sunt mancusos centum de auro mundo; et, si est uoluntas Dei ut accrescant iam dictas parias, similiter sit factum de ipsum acreximentum sicut est supra scriptum de hoc qui [...] modo: et ipso mense de Zaragoza sit omni tempore iulie, et ipsum de Lerida mense augusto; et, sic dederit iamdictus comes ullam de iam dictas parias, emendet hoc de alium suum auere usque predictas parias", R. Chesé Lapeña, Col·lecció diplomàtica de Sant Pere d'Ager, Doc. 39.

52 "Et iterum conuenit ei quod illi adiuuet ad tenere et ad abere suas terras et omnibus suis directis et omnias suas parias ex partibus Hispania, quas modo illi sunt in conuenientias ad dare aut in antea erunt, contra cunctos homines aut feminas qui illi hoc tulerint aut tollere uoluerint sine enganno de supradicto comite", R. Chesé Lapeña, Col·lecció diplomàtica de Sant Pere d’Ager, Doc. 42. 
visto repetida esta expresión en varias ocasiones y pensamos que es una manera breve de referirse a las taifas de Zaragoza y Lérida. Por el tono del texto, cabe deducir que Urgel, por alguna razón, ha perdido las parias que cobraba de Lérida y Zaragoza en algún momento entre agosto de 1058 y octubre de 1059.

Encontramos más referencias a Urgel como captador de parias posteriores a $1058^{53}$, pero en el marco del pacto firmado ese año entre Urgel y Barcelona el conde urgelense sólo contaría con un tercio de los ingresos, teniendo que ceder el resto al conde barcelonés. El resultado fue que Urgel incrementó su poder en la zona leridana pero que nunca fue un rival para la hegemonía barcelonesa.

\section{ELFINALDELREINADODERAMÓNBERENGUERI(1076): SUS DISPOSICIONES TESTAMENTARIAS}

Para finalizar con el gobierno de Ramón Berenguer I, analizaremos el famoso y controvertido testamento que otorga antes de morir en noviembre de 1076. La situación sucesoria a su muerte es la siguiente: Ramón Berenguer tenía un hijo de un matrimonio anterior, Pere Ramón y luego su tercera mujer, Almodís dio a luz a gemelos -Berenguer Ramón y Ramón Berenguer-. No se sabe exactamente si eran gemelos o no, pues Ramón Berenguer II Cap d'Estopes -llamado así por su pelo rubio, que semejaba estopa- recibe en algunos documentos el título de primogénito tras la huida de su hermano mayor Pere Ramón.

La política de compra de condados que hemos mencionado anteriormente pudo estar motivada, aparte de por la gran disponibilidad de ingresos procedentes de las parias, por un intento de Ramón Berenguer I de dotar a sus hijos nacidos de su segundo matrimonio con la condesa Almodís de territorio propio. Pero Pere Ramón, el heredero, temía que su padre, por influencia de su madrastra Almodís, dividiera el condado entre los tres hijos, como era costumbre en Barcelona, o aún peor, que él se viera excluido del reparto de la herencia. Por esta causa, asesina a su madrastra y tiene que huir a Al-Andalus huyendo de la ira de su padre.

Así, quedan como herederos únicos los -probablemente-gemelos. Ramón Berenguer I, en su testamento, reparte equitativamente todos sus bienes entre ambos, salvo Barcelona, cuyo palacio condal sería ocupado seis meses al año por cada uno.

Este arreglo acabó en 1082 con un misterioso accidente en el bosque en el que Ramón Berenguer II muere, sin descendencia, probablemente en un complot urdido por su hermano Berenguer Ramón. Este reinará sin oposición hasta 1097, cuando será sucedido por su sobrino Ramón Berenguer III, hijo del malogrado Cap d'Estopes.

En suma, entre los bienes que se repartían al 50 \% entre los hijos de Ramón Berenguer I aparecen, entre otros, "totas ipsas suas palias (sic) ${ }^{54}$, quas habebat qualiumque modo de ominbus partibus Hispaniarum per medium". No encontramos los lugares exactos que pagan parias, ocultos bajo ese vago "todas las partes de Hispania", pero suponemos que serían Zaragoza y Lérida, por ser los lugares de los que encontramos testimonio documental de que abonaran parias. El documento demuestra que en 1076 Barcelona seguía cobrando cantidades de dinero procedentes de los reinos taifas y que dichos pagos ya formaban parte del patrimonio del condado, ya que se reparten en un testamento. No es el primer testamento otorgado en la península ibérica en el que se hace referencia a parias, ya que Fernando I de Castilla había repartido en 1065 las parias que recibía entre sus tres hijos ${ }^{55}$.

53 N. Feliú de la Peña, J. Puyol y J. Sobrequés i Callicó, Anales de Cataluña, p. 307, año 1063.

54 Se refiere a parias, pero la palabra está mal escrita o transcrita.

55 E. Falqué (trad,), “Chronicón Compostellanum”, Habis, 14 (1983), p. 79. 


\section{CONCLUSIONES}

Hemos localizado unos 80 documentos fechados entre 1040 y 1070 que hacen referencia a pagos de parias de uno u otro modo. La mayoría son juramentos de vasallaje que ligan a Barcelona con otras entidades políticas, aunque también encontramos algunos que unen al conde de Urgel con otros nobles de su ámbito territorial. A mediados del siglo $\mathrm{XI}$, el único condado que amenaza la primacía barcelonesa es el de Urgel, pero Ramón Berenguer I consigue en sus pactos con este condado hacer patente su primacía, por ejemplo recibiendo dos tercios de las parias por un tercio que cobraba Urgel. En ninguno de los acuerdos que se conservan entre ambas entidades políticas podemos atisbar ni tan siquiera igualdad, siempre obtiene mejores condiciones el conde barcelonés que el conde pirenaico.

El conde de Urgel capta directamente algunos ingresos procedentes de los reinos taifas hasta 1058 y a partir de esa fecha redistribuirá a sus vasallos el dinero que le concede Barcelona en sus pactos. Ejerce una función en la zona pirenaica similar a la que desempeña Barcelona en el resto del ámbito catalán, pero a menor escala, incrementando así también su poder frente a nobles levantiscos como Arnau Mir de Tost.

Ramón Berenguer I era plenamente consciente de la necesidad de dominar el tráfico monetario que generaban las parias, por ello incluía cláusulas relativas a estos pagos en cada juramento de vasallaje que firmaba, incluso si lo hacía con nobles situados relativamente lejos de la frontera o con escaso potencial militar. Ello también puede ser debido a la utilización de formularios preestablecidos por parte de la cancillería del conde barcelonés. De hecho, probablemente a partir de la década de 1050 las parias fueran una cláusula estándar del contrato de vasallaje.

¿Qué reinos taifas eran los que pagaban? Encontramos referencia explícita a Zaragoza y a Lérida-Tortosa. La taifa de Zaragoza pagó parias a todas las entidades políticas cristianas del momento -Aragón, Castilla, Navarra y Barcelona- en algún momento de su historia. Los pagos a Barcelona desde la taifa hudí probablemente fueran reducidos y de corta duración en el tiempo. Por tanto, la mayoría de los ingresos procederían de Lérida-Tortosa, que fue protegida por Barcelona hasta la misma llegada de los almorávides.

Desde 1040, momento en el que presumiblemente comienza a afluir el dinero musulmán hacia Barcelona hasta 1076 el condado de Barcelona pasa de una situación de desgobierno a ser la principal entidad política del ámbito catalán. El impacto de las parias en esta evolución, como hemos tenido ocasión de analizar, es innegable. Contar con dinero fue la clave de la expansión barcelonesa del período, Ramón Berenguer I pudo comprar lealtades, expandirse a costa del territorio musulmán con el dinero, prevenir conflictos internos e incluso comprar directamente condados en el sur de Francia gracias al dinero musulmán. Las parias ejercieron un papel clave a la hora de situar al condado de Barcelona a la cabeza del resto de condados catalanes y en su expansión tanto a costa de los musulmanes incentivando a los nobles para que se instalaran en zonas de la frontera como hacia el norte, mediante la compra de condados.

Los pagos de parias tienen también una vertiente ideológica muy importante, ya que una parte importante del dinero se entregaba a la Iglesia en forma de donaciones. Estas donaciones perseguían dos objetivos: el primero, agradecer la ayuda divina que había permitido someter a los infieles a los pagos, interpretación que va en línea con la concepción providencialista de la Historia que se tenía en aquel momento y, el segundo, demostrar a la sociedad el poderío militar del conde, que le permitía extraer esos ingresos de territorio musulmán.

En conclusión, los abonos de parias que Barcelona captó de los reinos de taifas de Zaragoza, Lérida y Tortosa le permitieron recuperar y afianzar su posición hegemónica 
sobre el resto de condados catalanes, dirigiendo la política de los mismos hasta la unión de Cataluña y Aragón a finales del siglo XII.

\section{BIBLIOGRAFÍA:}

Balañá i Abadía, P., Els musulmans à Catalunya (713-1153): assaig de síntesi orientativa, Sabadell, Ausa, 1993.

Balari Jovany, J., Orígenes Históricos de Cataluña, San Cugat del Vallès, Instituto internacional de cultura románica, 1964, (1ºd. 1899).

Baraut, C., "Els documents, dels anys 1051-1075, de l'Arxiu Capitular de la Seu d'Urgell" en Urgellia, 6 (1983), p. 239

Bonnassie, P., La Catalogne du milieu du $X^{e}$ a la fin $d u$ XI Siècle, Croissance et mutations d'une sociètè, Tome II, Tolouse, Université de Tolouse-Le Mirail, 1975.

Bonnassie, P. Cataluña mil años atrás (siglos X-XI), Barcelona, Península, 1988.

Chesé Lapeña, R., Col-lecció diplomàtica de Sant Pere d'Ager fins 1198, Volum I, Barcelona, Fundación Noguera, 2011

Dèbax, H., "Les feudalitats al Llenguadoc i Catalunya. Algunes observacions sobre les divergències de l'evolució", L'Avenç, 202, 1996, pp. 30-35.

Falqué, E. (trad,), "Chronicón Compostellanum", Habis, 14 (1983), pp. 73-84.

Feliú de la Peña, N., Puyol, J. y Sobrequés i Callicó, J., Anales de Cataluña, Barcelona, Base, 1999.

Feliu i Montfort, G. y Salrach, J.M., Els pergamins de l'Arxiu Comtal de Barcelona de Ramon Borrell a Ramon Berenguer I, Lérida, Fundación Noguera-Pagés, 1999.

Fité i Llevot, F. y González i Montardit, E., Arnau Mir de Tost: Un señor de frontera al segle $X I$, Lérida, Universidad de Lérida.

Joranson, E., The Danegeld in France, Rock Island (Illinois), Augustana Printers, 1923.

Kosto, A.J., Making agreements in medieval Catalonia: power, order and the written world, 1000-1200, Cambridge, Cambridge University Press, 2001

Laliena, C., La formación del Estado feudal: Aragón y Navarra en la época de Pedro I, Huesca, Colección de estudios Altoaragoneses, 1996.

Mínguez Fernández, J. M., La España de los siglos VI al XIII: guerra, expansión y transformaciones, Nerea, Pamplona, 2004.

Negro Cortés, A. E., "Las parias abonadas por el reino de Granada (1246-1464). Aproximación a su estudio", Roda da Fortuna, 2, 1-1 (2013), pp. 382-396.

Negro Cortés, A.E., "Las parias: una introducción general" en F. Sabaté y J. Brufal (ed.) Investigar l'edat mitjana, Lérida, Pagés Editors, 2018, pp. 43-53.

Negro Cortés, A. E., "Las parias en la historia medieval española" en M. Urraco y S. López (ed.) Catálogo de Investigación Joven de Extremadura, Cáceres, Universidad de Extremadura, 2017, pp. 255-258.

Negro Cortés, A. E., "Explotación económica de los musulmanes del valle del Ebro: parias y almotexenas abonadas a los reinos de Aragón y Navarra durante el siglo XI", Aragón en la Edad Media, 28 (2018), pp. 4-17.

Puig i Cadafalch, J., Falguera, A. y Goday i Casals, J., L'Arquitectura romanica a Catalunya, Vol II, Institut d'Estudis Catalans, Barberà del Vallés, 2001, (ed. facsímil).

Rosell, F. M., Liber Feudorum Maior: cartulario real que se conserva en el Archivo de la Corona de Aragón, Barcelona, CSIC, 1945.

Ruiz-Doménec, J. E., "Cataluña en 1025: los orígenes de una organización social", Estudi General, 1-1 (1996), pp. 93-98.

Ruiz-Domènec, J. E., L'Estructura feudal: sistema de parenitu i teoria de l'aliança en la societat catalana (c. 980-c. 1220), Edicions del Mall, Sant Boi de Llobregat, 1985 
Sabaté, F., La feudalización de la sociedad catalana, Granada, Universidad de Granada, 2007.

Sabaté, F., Història de Lleida. Volum 2: Alta Edad Mitjana, Pagès, Lérida, 2003.

Salrach, J. M., Història de Catalunya, Volum II: El procés de feudalització (segles III-XII), Barcelona, Edicions 62, 1987.

Sobrequés, S., Els grans comtes de Barcelona, Barcelona, Vincens Vives, 1961.

Villanueva, J., Viage literario á las iglesias de España, Tomo 10, Madrid, Real Academia de la Historia, 1821,

Zimmermann, M., "Et je t'empouvoirrai (potestativum te farei), à propos des relations entre fidélité et pouvoir en Catalogne au Xle siècle", Mediévales, 10, 1986, pp, 17-36.

Zurita, J., Anales de Aragón, (ed. A. Canellas), Institución Fernando el Católico, CSIC, Zaragoza, 1976. 